\title{
A Study on the Impact of Existing and Emerging Trends in Digital Marketing on Consumer Buying Behavior
}

\author{
Dr. Nirav B. Halvadia \\ Associate Professor, St. Kabir Institute of Professional Studies \\ dr.nirav@skips.in
}

Shreya Menon

PGDM student, St. Kabir Institute of Professional Studies

Shreya19@skips.in

\begin{abstract}
:
Digital marketing is one of the important components of marketing that uses the internet as well as the online platforms, digital media, and technologies for the promotion of services/goods. Digital marketing has become almost inevitable for brands and marketers. Nowadays, from clothes to medicine, everything reaches our doorstep within a few clicks. Content marketing, social media marketing, search engine marketing, email marketing, display advertising, influencer marketing, interactive marketing, chatbot, visual search, etc. are existing and emerging trends of digital marketing. The purpose of this research is to find out the impact of the existing and emerging trends in digital marketing on consumer buying behavior and up to what extent these trends affect the consumers.

Descriptive research - the type of conclusive research was conducted for achieving the objectives of the study. Data were collected from 136 respondents who are exposed to digital marketing strategies using the non-probability convenience sampling method. The findings of the study suggested that existing trends such as social media marketing, content marketing, search engine marketing, and display advertising create an impact on consumer buying behavior. Whereas emerging trends such as visual search, interactive marketing, influencer marketing, and personalization have a significant impact on consumer buying behavior.
\end{abstract}

\section{Keywords:}

Digital Marketing, Consumer Behavior, Digital Marketing Trends, Online Marketing, Content Marketing, Social Media Marketing. 


\section{Introduction:}

Nowadays, from clothes to medicine, everything reaches our doorstep within a few clicks. Everything in today's time is getting digitalized, marketing strategies also. Digital marketing, in the current era of the internet, has completely changed the scenario of marketing. Digital marketing is one of the important components of marketing that uses the internet as well as the online platforms, digital media, and technologies for the promotion of services/goods. The importance of digital marketing is increasing day by day with the increase in internet adoption and internet data consumption. Digital marketing has become almost inevitable for brands and marketers now. Digital marketing is such a platform where trends keep on evolving and marketers and companies need to understand such trends and implement such strategies for their business as well. Content marketing, social media marketing, search engine marketing, email marketing, display advertising, influencer marketing, interactive marketing, chatbot, visual search, etc. are existing and emerging trends of digital marketing. These current and emerging trends of digital marketing create a huge impact on consumer buying behavior. The purpose of this research is to find out the impact of the existing and emerging trends in digital marketing on consumer buying behavior and up to what extent these trends affect the consumers. This study not only helps in knowing the effectiveness of these trends but can also help marketers and companies in identifying the existing \& emerging trends and what are the strategies that should be adopted by the companies for customer satisfaction and reach. All these trends could help the company to get a competitive edge and be relevant in the market.

Now many trends in digital marketing have been existing for quite some time and are some trends have been picking up recently and are emerging rapidly. Technology is ever-evolving and it is something that neither customers nor companies can ignore. Everybody has to adhere to the technological changes. So the faster the companies get used to these trends, the better competitive edge they can have in digital marketing. Hence is very important for the companies or the marketer to leverage these trends. Many researchers have worked on the current and emerging trends in digital marketing. But very little effort is devoted to studying the impact of various existing and emerging trends of digital marketing on consumer buying behavior. Keep this in mind, the following objectives were framed:

- To understand the existing and emerging trends in digital marketing.

- To understand the impact of existing and emerging trends in digital marketing on consumer buying behavior.

\section{Literature review:}

Digital marketing is a booming sector in the current scenario. Its relevance has become so important nowadays that the companies cannot afford not to tap into this segment. Digital marketing refers to marketing or promotion done through various digital platforms (A.I. Klimin, D.V. Tikhonov, A.I. Riushenkova, 2018). Digital marketing in the digital allows companies to sell their products \& services and also provides them with online customer service. 
Digital marketing won't replace traditional marketing, but it can merely complement it, bring better opportunities for the firms to stay in contact with the customer (A.I. Klimin, D.V. Tikhonov, A.M. Efimov, 2017). Amita Chourisya (2017). Nowadays, the value of digital marketing has been realized by businesses in the developing world. To succeed in the business, it has become inevitable for the businesses to integrate traditional and online marketing to cater to the consumer needs more precisely (Parsons, Zeisser, Waitman, 1996). Online marketing is leveraging the unique capabilities of new interactive media to create a new form of interactions and transactions between consumers and marketers.

(Amita Chourisya, 2017) Online marketing leverages the unique capabilities of digital interactive media to generate new types of customer-marketer interactions as well as transactions. In digital marketing, there has been a lot of current/emerging trends, and these trends are very important because these trends play a significant role in attracting customers and these trends also help the company remain competitive in the market. Companies are nowadays trying to leverage all these trends for maximizing their reach, profit, and for increasing brand awareness.

Earlier it was difficult for a small-scale business to grow and reach its potential customers which was majorly due to the high advertisement and marketing cost. It also restricted the small business to limit themselves to a particular geographical location. Due to the emergence of digital marketing, small businesses are also getting an opportunity to market themselves at a low cost. Online marketing has an impressive return on investment (ROI). It is mostly because it gives amazing reach at a low cost. Nowadays, people are also drifting more towards digital platforms rather than the traditional medium.

\section{Existing trends in digital marketing:}

According to the (Content marketing institute, 2015), Content marketing is a strategic marketing approach, which focuses on the distribution and creation of relevant, consistent, and valuable content for attracting as well as retaining a clearly defined audience to drive profitable customer action. Content marketing can be done in a lot of ways like blogs, creating videos, memes, posts, illustrations infographics, etc. Content marketing is a very smart way of persuading customers without actually promoting a product/service. Many of the companies create such contents that invoke a need in a customer towards buying a product or a service.

Social media is not a new trend in digital marketing, but its popularity and influence have been increasing day by day. Social media is an important digital marketing tool because it lets the company interact and engage with its brand. Social media can be used for creating leads, brand awareness, and sales. Social media is majorly filled with graphical content. In social media, marketers have already understood the graphical content and images are far more successful than the traditional texts for reaching out to their potential customer as well as their communities on social media platforms (Kissane, D., 2016). In social media platforms, marketers have various options for branding within the social media landscape, such as participating as a brand persona in social media platforms, paid advertisements, creating engagement activities for consumer participation, and publishing branded content (Tute $n \&$ 
Solomon, 2013). Talking about social media its main benefits are customer awareness, better SERP ranking, more inbound traffics, higher conversions, more brand authority, improved brand loyalty, cost-effectiveness, and better customer satisfaction.

Search engine marketing is one of the prominent trends in digital marketing and one of the most effective ways to grow a company's online business. Search engine marketing is the marketing practices undertaken by companies/marketers by using paid advertisements on SERPs (Search engine result pages.) search engine marketing requires proper optimization techniques for better ranking and visibility. Visibility has a great impact on customer's purchase decisions. Through effective search engine optimization strategies even the less popular companies can appear ahead of the popular, well-known brands. (Kai H. Lim 2010). Search engine marketing requires proper optimization techniques for better ranking and visibility. Visibility has a great impact on customer's purchase decisions. (Ambuli Velayudham, Surendher Rose 2019), the impact of search engines on the consumer buying decision is linked with higher brand listing and information search. Although the marketing scope has expanded due to the digital mode, most people appear to have a conventional buying behavior and tend to refer to search engines for services or products and informational search that has a higher ranking.

Email marketing is the way of sending commercial emails to a company's potential or existing customers. It is a very simple yet powerful tool of marketing. The reason why Wreden (1999) defined email marketing as the 'Internet's killer application' is because of the precision with which email can be targeted, monitored, and personalized. Companies can market at low costs and digital processing enables the businesses to send out large amounts of emails. Email marketing not only helps in promoting the brand but also helps in personalizing the content. It not only helps you establish direct contact with the customers but it also helps in driving inevitable consumers to your website (Gupta, B., 2019). According to the qualitative research carried out by (Rettie, R., 2002), email marketing would be more beneficial as a retention tool rather than as a customer acquisition tool as its interactivity enables two-way communication. Hence it should be integrated with the overall communication mix of the company. Email marketing can be used as both retention as well as an acquisition tool and it also has a significant impact on the buying behavior of the consumers.

Display advertisings are the graphic advertising that can be seen on websites, social media platforms, or apps. These advertisements have various formats such as images, flash, videos, texts, audio, etc. Display advertising is an important trend because its mere exposure (even without requiring the customer/user to engage with the advertisement) can attract the consumer attention towards the marketer's product and brand (Ghose, A., \& Todri, V., 2015). The main objective of the display advertisements is to create brand awareness. These advertisements help in retaining these advertisements in the mind of customers, which could also trigger the possibility of the user researching about the brands that they saw on the display advertisement. These advertisements are very popular and common and the display ads also help with the conversions done through retargeting. 


\section{Emerging trends in digital marketing:}

Influencer marketing has been very much in trend these days and its relevance is also increasing significantly. Influencer marketing in a nutshell means endorsing a product or service through an influencer. In Influencer marketing, the brands or the companies use influencers i.e. "the normal people" with lots of followers on their social media accounts, to push or endorse the brand's message (Tapinfluence, 2017). Influencer marketing is very much popular on the platforms like Facebook, YouTube, and Instagram, etc. Influencer marketing is very relevant because the information passed on by the influencers increases credibility as their followers tend to trust them. (Sudha, M., \& Sheena, K. 2017) influencer marketing has various applications and influencer marketing is used by the marketer to drive in-store or online sales of their products/services, for creating social conversations for the brand, and to establish the credibility of their company. Nowadays people are also becoming more conscious and informed. A good influencer who provides valuable content and information can greatly attract a good number of users. Hence companies can leverage this opportunity by collaborating with a well-informed, good content provider

In interactive marketing, the company tries to make a one on one communication with their customers. (Techakana, J., 2020) consumers are always looking for interactions and new experiences. They would rather prefer interactive $\&$ visual content over the traditional formats. The research was carried out by ExpoTV.com which indicated that about $89 \%$ of the respondents' mentioned that they felt more loyal towards the brand if they were asked to provide constructive feedback. Here the customer engagement plays an important role for the company. Consequently, companies are devoting their resources for strategically steering consumer engagement like hiring full-time managers (Verhoef, P. C., Reinartz, W. J., \& Krafft, M., 2010) Interactive markets can be done through polls, online contents, quizzes, emails, etc.

Chatbots are the AI i.e. the artificial intelligence software that simulates a chat or a conversation in a natural language, to the users through various websites, messaging applications, and telephone or mobile applications. These Chatbots are also sometimes known as the Chatterbots. These chatterbots facilitate in stimulating a "chatter" or a conversation of a human through voice or text interactions. Chatbot apps streamline communications between services and users, improving the experience of customers. Chatbots are very useful in reducing customer care costs and improving customer-brand engagement.

Visual searches can be a game-changer in digital marketing. Virtual searches mean that instead of putting text, screenshots or images are used as a stimulus for internet searches. To understand the content and meaning of these images and return a list of relevant results, modern visual search technology uses AI (artificial intelligence). Visual search can be very convenient for the customers as they'll be shown the same or the related product that they put in as their search input. Here the companies can use relevant keywords with high-quality images and list them in their online inventory. Many academic institutions and companies are focusing on new paradigms for visual searches such as sketches, similar images, and icons. These would also have the potential to provide the user with the majority of the web info (Lew, M. S. (2000). This digital marketing trend would be extremely beneficial in the coming time for the 
companies as they can provide the user with the exact or the related thing that they are looking for. This can also help with the conversion rate.

Personalization in marketing refers to the implementation of such strategies that could deliver customized/individualized content to the user or the recipient by collecting data, use of AI, and data analysis. Personalization also helps in CRM. Nowadays people prefer more personalized content, product/services, and ads. Companies have been trying to leverage personalized ads as well. Personalized customer experience not only creates loyalty but also drives revenue (Akimova, O., 2019).

Based on the literature review the following hypotheses were framed:

H1: The digital marketing trend- content marketing, has an impact on consumer buying behavior.

H2: The digital marketing trend- Social media marketing, has an impact on consumer buying behavior.

H3: The digital marketing trend- Search engine marketing, has an impact on consumer buying behavior.

H4: The digital marketing trend- Email Marketing, has an impact on consumer buying behavior.

H5: The digital marketing trend- Display Advertising, has an impact on consumer buying behavior.

H6: The digital marketing trend- Influencer marketing, has an impact on consumer buying behavior.

H7: The digital marketing trend- Interactive Marketing, has an impact on consumer buying behavior.

H8: The digital marketing trend- Chatbots, has an impact on consumer buying behavior.

H9: The digital marketing trend- Visual search, has an impact on consumer buying behavior.

H10: The digital marketing trend- Personalization, has an impact on consumer buying behavior.

\section{Research methodology:}

Descriptive research - the type of conclusive research was conducted for achieving the objectives of the study. Data is collected from 136 respondents who were exposed to digital marketing strategies using the online survey method. Because of not having proper 
information about the target population, the non-probability convenience sampling method was used to select respondents. The online questionnaire was used to collect data from respondents. The questionnaire had statements measuring the impact of current and emerging trends of digital marketing. These statements were taken from past research work in a similar area.

\section{Data analysis and interpretation:}

One sample t-test was used to study the impact of various digital marketing trends on consumer buying behavior. The following table shows the out of hypotheses testing:

\begin{tabular}{|c|c|c|c|c|}
\hline Hypotheses & $\begin{array}{l}\text { Mean } \\
\text { value }\end{array}$ & T-value & P-value & Result \\
\hline $\begin{array}{l}\text { The digital marketing trend- content } \\
\text { marketing, has an impact on consumer } \\
\text { buying behavior. }\end{array}$ & 3.43 & 4.743 & 0.000 & $\begin{array}{l}\text { Hypothesis } \\
\text { is accepted }\end{array}$ \\
\hline $\begin{array}{l}\text { The digital marketing trend- Social } \\
\text { media marketing, has an impact on } \\
\text { consumer buying behavior. }\end{array}$ & 3.46 & 5.091 & 0.000 & $\begin{array}{l}\text { Hypothesis } \\
\text { is accepted }\end{array}$ \\
\hline $\begin{array}{l}\text { The digital marketing trend- Search } \\
\text { engine marketing, has an impact on } \\
\text { consumer buying behavior. }\end{array}$ & 3.51 & 6.525 & 0.000 & $\begin{array}{l}\text { Hypothesis } \\
\text { is accepted }\end{array}$ \\
\hline $\begin{array}{l}\text { The digital marketing trend- Email } \\
\text { Marketing, has an impact on consumer } \\
\text { buying behavior. }\end{array}$ & 3.08 & 0.845 & 0.399 & $\begin{array}{l}\text { Hypothesis } \\
\text { is rejected }\end{array}$ \\
\hline $\begin{array}{l}\text { The digital marketing trend- Display } \\
\text { Advertising, has an impact on consumer } \\
\text { buying behavior. }\end{array}$ & 3.66 & 8.546 & 0.000 & $\begin{array}{l}\text { Hypothesis } \\
\text { is accepted }\end{array}$ \\
\hline $\begin{array}{l}\text { The digital marketing trend- Influencer } \\
\text { marketing, has an impact on consumer } \\
\text { buying behavior. }\end{array}$ & 3.04 & 0.443 & 0.000 & $\begin{array}{l}\text { Hypothesis } \\
\text { is accepted }\end{array}$ \\
\hline $\begin{array}{l}\text { The digital marketing trend- Interactive } \\
\text { Marketing, has an impact on consumer } \\
\text { buying behavior. }\end{array}$ & 3.68 & 8.194 & 0.000 & $\begin{array}{l}\text { Hypothesis } \\
\text { is accepted }\end{array}$ \\
\hline $\begin{array}{l}\text { The digital marketing trend- Chatbots, } \\
\text { has an impact on consumer buying } \\
\text { behavior. }\end{array}$ & 3.15 & 1.543 & 0.125 & $\begin{array}{l}\text { Hypothesis } \\
\text { is rejected }\end{array}$ \\
\hline $\begin{array}{l}\text { The digital marketing trend- visual } \\
\text { search, has an impact on consumer } \\
\text { buying behavior. }\end{array}$ & 3.91 & 11.932 & 0.000 & $\begin{array}{l}\text { Hypothesis } \\
\text { is accepted }\end{array}$ \\
\hline $\begin{array}{l}\text { The digital marketing trend- } \\
\text { personalization, has an impact on } \\
\text { consumer buying behavior. }\end{array}$ & 3.51 & 6.111 & 0.000 & \\
\hline
\end{tabular}


As per the above table, $\mathrm{p}$ values for content marketing,social media marketing, search engine marketing, display advertising, influencer marketing, interactive marketing, visual search, and personalization is less than 0.05 . So. It is inferred that content marketing, social media marketing, search engine marketing, display advertising, influencer marketing, interactive marketing, visual search, and personalization have a significant impact on consumer buying behavior.

As per the above table, $\mathrm{p}$ values of email marketing and chat boat is less than 0.05 . So, it is inferred that there is no significant impact of email marketing and chatbots on consumer buying behavior.

\section{Findings:}

The findings of the study suggest that existing trends such as social media marketing, content marketing, search engine marketing, and display advertising impacts consumer buying behaviour. Whereas emerging trends such as visual search, influencer marketing, interactive marketing, and personalization have a significant impact on consumer buying behavior. Other indications of the findings are that the majority of the respondents believe that social media influences the consumer purchase decisions. The majority of respondents find search engine ads to be relevant and they also agree that display advertisements help in retaining and remembering the brand. Informational content, blogs, posts, etc. are part of content marketing and many people refer to these contents for making purchase decisions. Emerging trends such as visual searches are gaining a lot of popularity and have a great scope in the upcoming time. Personalized content and display advertising are also preferred by the majority of the respondents. Interactive marketing was not prevalent a few years back but nowadays brands are investing a lot of time in interactive marketing and trying to establish continuous communications with their customers and the majority of the responses also indicate its relevance and preference.

\section{Managerial implications:}

Content is king and through this research, it was found that it has a significant impact on the consumers. So the companies and marketers should always focus on providing good content because not only it increases the ranking but it also educates the consumer about the products/services of the company. It is also an excellent off-page SEO optimization technique. A good piece of content would also attract the customer towards the brands offering. Hence content marketing is one of the most important trends of social media.

Through proper search and display advertisement strategies, the marketers and the brands can increase their reach, conversions, and brand awareness. Paid advertisements are very important because they have a better chance of ranking. Getting organic traffic by ranking can be very difficult and time-consuming. Hence paid advertisements should not be avoided by the companies. Social media marketing will remain evergreen as throughout the years the average time spent on social media has been consistently increasing. In social media strategies such as 
interactive marketing and influencer marketing are gaining momentum. Advertisements on social media are also very beneficial because social media has a large number of users and it is the best platform to advertise. Talking about influencer marketing, companies should majorly focus on strategies that could potentially influence Gen $\mathrm{Z}$ and millennials. It is because the majority of the followers of the influencers fall under this category.

Companes should adopt a visual search strategy as early as possible because visual search allows consumers to browse for their desired item and often opens up all the related products that they would prefer. This also saves a lot of time for the consumers. Nowadays companies are also coming up with this feature on their website or application.

\section{References:}

1) Klimin A.I., Tikhonov D.V. \& Riushenkova A.I. (2018). Use of elements of native advertising in order to improve the effectiveness of media campaigns. Proceedings of the 32nd International Business Information Management Association Conference, IBIMA 2018 - Vision 2020: Sustainable Economic Development and Application of Innovation Management from Regional expansion to Global Growth. Spain, 1(1), pp. 8304-8310.

2) Klimin, A.I., Tikhonov, D.V. \& Efimov, A.M. (2017). Evaluation of the effectiveness of marketing communications in Russian business using the example of St. Petersburg enterprises. Proceedings of the $30^{\text {th }}$ International Business Information Management Association Conference, IBIMA 2017 - Vision 2020: Sustainable Economic Development, Innovation Management, and Global Growth. Spain,1(1), pp. 1465-1482.

3) Wymbs, C. (2011). Digital marketing: The time for a new "academic major" has arrived. Journal of Marketing Education, 33(1), 93-106.

4) Chourasiya, A. (2017) Online marketing Impact on society, IJEDR Vol 5 issue 9.

5) Content Marketing Institute: Benchmarks, Budgets, and Trends - North America - 2015.

6) Balteș, L.P. (2015). Content marketing - the fundamental tool of digital marketing. Bulletin of the Transilvania University of Brasov. Series $V$ : Economic Sciences, 111-118.

7) Kissane, D. Twenty trends in digital marketing for 2016. URL: www. doz. com.

8) Tuten, T., \& Solomon, M. (2013). Social media marketing. Upper Saddle River, NJ: Pearson.

9) Ambuli Velayudham, Surendher Rose (2019), "Impact of Search Engine Marketing Towards Customer Purchase Behavior", International Journal of Research and Innovation in Applied Science (IJRIAS), 4 (!2),PP. 2454-6194. 
10) Dou, W., Lim, K. H., Su, C., Zhou, N., \& Cui, N. (2010). Brand positioning strategy using search engine marketing. MIS quarterly, 261-279.

11) Gupta, B. (2019). Online Marketing-Emerging Trends and issues-A Review. Journal of the Gujarat Research Society, 21(16), 2063-2071.

12) Parsons, A. J., Zeisser, M. \& Waitman, R. (1996). Organizing for digital marketing. McKinsey Quarterly.

13) Ghose, A., \& Todri, V. (2015). Towards a digital attribution model: Measuring the impact of display advertising on online consumer behavior.MIS Quarterly, 40(4), pp. 889-910. DOI:HTTPS:// DOSI.ORG/10.25300/MISQ/2016/40.4.

14) Sudha, M., \& Sheena, K. (2017). Impact of influencers in the consumer decision process: the fashion industry. SCMS Journal of Indian Management, 14(3), 14-30.

15) Techakana, J. (2020). Book review: 130 trends and predictions for digital marketing 2020. Journal of the Association of Researchers, 25(2), 475-492.

16) Følstad, A., \& Brandtzæg, P. B. (2017). Chatbots and the new world of HCI. Interactions, 24(4), 38-42.

17) Lew, M., S. (2000). Next-generation web searches for visual content. Computer, 33(11), 46-53.

18) Slijepčević, M., \& Radojević, I. (2018). Current trends in digital marketing communication. Faculty of Management, Belgrade Metropolitan University.

19) Akimova, O. (2019). Tracking user behavior on the web for digital marketing personalization with Salesforce.

20) Verhoef, P. ,C., Reinartz, W., J., \& Krafft, M. (2010). Customer engagement as a new perspective in customer management. Journal of service research, 13(3), 247-252.

21) https://www.bluefountainmedia.com/blog/advantages-of-social-media-marketing

22) Wreden, N. (1999). Mapping the Frontiers of E-mail Marketing. Harvard Business Review.

23) Rettie, R. \& Chittenden, L. (2002). Email marketing: success factors. Kingston Business School, Kingston University. Available at: https://eprints.kingston.ac.uk/id/eprint/6395/1/Rettie-R-6395.pdf 
24) https://searchcustomerexperience.techtarget.com/definition/chatbot.

25) https://www.tapinfluence.com/blog-what-is-influencer-marketing.

$$
* * * * * * * * * *
$$

